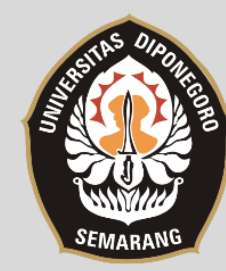

pISSN : $1829-8370$ eISSN : 2301-9069

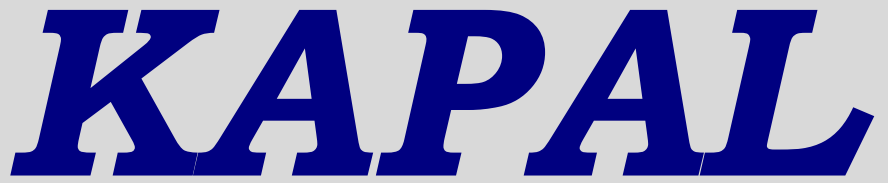

JURNAL ILMU PENGETAHUAN \& TEKNOLOGI KELAUTAN

\title{
Analisa Perubahan Panjang Model FPU Barge Terhadap Koefisien Linier dan Kuadratik Roll Damping
}

\author{
Baharuddin Ali ${ }^{1 *}$, Mahendra Indiaryanto ${ }^{1)}$, Chandra Permana ${ }^{1)}$, Widodo ${ }^{1)}$ \\ ${ }^{1)}$ Balai Teknologi Hidrodinamika - BPPT \\ Jl. Hidrodinamika (komplek ITS) Sukolilo - Surabaya, Indonesia 60111
}

disubmit pada $: 01 / 08 / 18 \quad$ direvisi pada $: 12 / 09 / 18 \quad$ diterima pada $: 22 / 10 / 18$

\begin{abstract}
Abstrak
Roll damping sangat berperan penting pada maksimum roll terutama pada daerah resonansi disekitar roll natural period. Dalam prediksi gerak roll, prediksi roll damping dilakukan dengan metode difraksi radiasi yang menambahkan viscous roll damping dari formulasi semi empiris maupun dari uji roll decay. Pada uji roll decay akan didapatkan koefisien komponen roll damping linier dan quadratik yang selanjutnya diperlukan dalam perhitungan nilai roll damping. Nilai koefisien roll damping ini bisa diperoleh dengan melakukan fitting hasil uji roll decay dengan metode Froude maupun Bertin. Pada studi ini dilakukan analisa terhadap perubahan roll damping dan akibatnya terhadap gerak roll pada dua buah model FPU barge yang identik namun berbeda dimensi. Perubahan dimensi model benda apung akan menimbulkan perubahan pula pada karakteristik koefisien linier maupun quadtatik roll dampingnya. Dari hasil pengujian model diketahui bahwa pengurangan dimensi panjang model dengan posisi relatif titik berat dan jarijari girasi roll tetap akan menaikan nilai koefisien roll damping $21 \%$ dari desain induknya. Kenaikan nilai koefisien roll damping didominasi oleh komponen linier. Dengan adanya kenaikan koefisien roll damping pada model yang lebih pendek menyebabkan turunnya nilai respon gerak roll melalui uji seakeeping.
\end{abstract}

Copyright @ 2018, KAPAL, pISSN:1829-8370, eISSN : 2301-9069

Kata Kunci : roll damping, linier komponen,quadratik komponen, roll decay

\section{PENDAHULAN}

Penggunaan bangunan apung dengan desain dasar barge (seperti FSO, FPSO,FPU, dan FSRU) untuk mendukung eksplorasi minyak, gas maupun berfungsi lain di lepas pantai dengan berbagai pertimbangan telah banyak menjadi pilihan. FPU (Floating Production Unit), sebagai salah satu alternatif bangunan apung yang digunakan dalam eksplorasi minyak dan gas. Pada kasus tertentu, proses produksi di FPU terganggu atau tertunda dengan adanya gerakkan roll. Sehingga, pemodelan yang akurat pada prediksi gerak roll dalam tahap desain menjadi sangat penting.
Sebagaimana diketahui pada prediksi gerak roll adalah sangat sulit dibanding dibandingkan dengan mode gerak lain, hal ini terbukti sering kekurang akuratan dalam prediksi gerak roll, hal ini terjadi karena metode prediksi gerak kapal yang umum digunakan tidak memasukkan efek viskositas pada roll damping. Sehingga dalam memprediksi gerak roll damping digunakan metode empiris. Masukkan yang akurat nilai viscous roll damping akan membantu akurasi prediksi gerak roll.

Pengujian roll decay sering dilakukan sebagai bagian dari program uji model seakeeping, uji ini digunakan untuk menentukan roll damping

*) Penulis Korespondensi :

Email : baharuddin.ali@bppt.go.id 
karakteristik model. Beberapa peneliti telah melakukan prediksi roll damping untuk FPSO Yuck et.al.,[1] dan Park et.al., [2]. Metode prediksi untuk roll damping paling banyak dikembangkan oleh Ikeda et.al. [3][4] dengan melalui serangkain pengujian model. Juga studistudi tentang roll damping bangunan lepas pantai tekait decay test dilakukan oleh Fernandes et. al. [5][6].

Dalam tahap perencanaan, perubahan variabel dimensi yang mungkin terjadi perlu pula dilakukan kajian pengaruhnya terhadap gerak roll. Pada penelitian terdahulu seperti [7][8], studi roll damping dilakukan fokus pada sebuah model, sedangkan pada penelitian ini dilakukan kajian tentang karakteristik roll damping melalui uji roll decay serta pengaruhnya pada seakeeping pada dua buah model FPU barge identik dengan berbeda dimensi panjang.

\section{METODE}

\subsection{Uji Model}

Untuk mendapatkan nilai koefisien roll damping, pengujian roll decay dilakukan pada dua buah model FPU (Model-A dan Model-B) dengan bentuk dasar sebuah barge, gambar facet model seperti terlihat pada Gambar 1. Kedua model memiliki bentuk yang identik namun berbeda panjangnya, Model-B lebih pendek dibandingkan dengan Model-A. Ukuran utama dari kedua model disajikan pada Tabel 1.

Kegiatan pengujian ini dilakukan di fasilitas kolam uji maneuvering ocean basin (MOB) Laboratorium Hidrodinamika Indonesia - BPPT, Surabaya.

Tabel 1. Ukuran utama model

\begin{tabular}{clcc}
\hline No & \multicolumn{1}{c}{ Parameter } & Model A & Model B \\
\hline 1 & L (m) & 4,00 & 3,81 \\
2 & $\Delta(\mathrm{kg})$ & 594,16 & 564,43 \\
3 & B (m) & 1,01 & 1,01 \\
4 & T (m) & 0,15 & 0,15 \\
5 & VCG/T (-) & 1,92 & 1,92 \\
6 & LCG/L (-) & 0,51 & 0,51 \\
7 & Kxx/B (-) & 0,35 & 0,35 \\
8 & Kyy/L (-) & 0,25 & 0,25 \\
\hline
\end{tabular}

Gambar 1. Facet model FPU barge
Pada pengujian decay, gerakkan heeling model dilakukan menekan model dengan pelan pada salah satu sisi kapal secara manual hingga mencapai sudut roll yang dikehendaki kemudian dilepaskan, sehingga model mengalami gerak roll. Selama pengujian model diusahakan bergerak pada mode gerak roll dengan meminimalisasi mode gerak lain serta kondisi air harus tenang.

Sebagai konfirmasi perubahan roll damping akibat perubahan dimensi barge maka dilakukan pengujian seakeeping pada kedua model tersebut. Pengaturan model di kolam saat uji seakeeping dilakukan dengan menambat model pada empat titik sistem tambat yang masing-masing titik dilengkapi dengan sistem pegas yang diatur sedemikian rupa sehingga keseluruhan kekakuan pegas tidak mengganggu gerakkan model. Pengujian dilakukan pada kondisi gelombang ireguler dengan tinggi gelombang siknifikan $\mathrm{Hs}=$ $0.043 \mathrm{~m}$ dan peak period $\mathrm{Tp}=0.920 \mathrm{sec}$, tipe spektrum JONSWAP dengan arah heading model terhadap gelombang $90 \mathrm{deg}$.

Data gerak model kapal direkam dengan menggunakan sistem wireless optical tracking motion, sehingga model dapat bergerak dalam 6 derajat kebebasan. Sensor target yang terpasang pada model akan dideteksi oleh camera khusus mendeteksi gerakkan model. Semua sistem akuisisi data sebelum dilakukan pengujian terlebih dahulu dilakukan kalibrasi sehingga didapat hasil yang akurat.

\subsection{Pengolahan Data Roll Decay Test}

Untuk mendapatkan koefisien roll damping dari pengujian decay test dilakukan pengolahan data berupa time trace gerak roll seperti contoh Gambar 1.

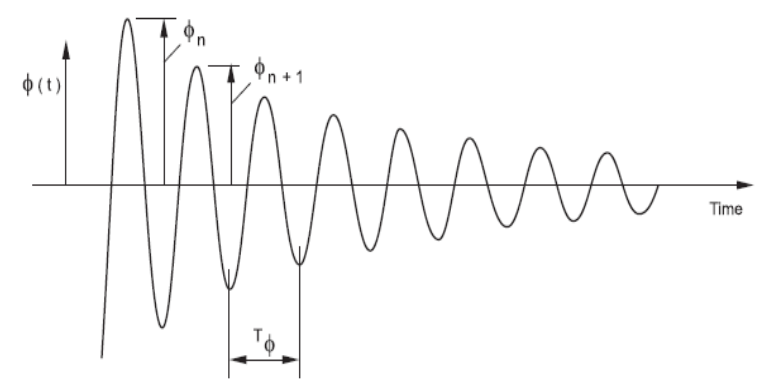

Gambar 1. Time trace uji roll decay

menurut Froude [9] penurunan amplitudo roll pada uji roll decay $\Delta \phi$ yang didefinikan sebagai bentuk polynomial fungsi $\phi_{m}$ :

$\Delta \phi=a \phi_{m}+b \phi_{m}^{2}$ 
sedangkan menurut Bertin pengurangan amplitudo roll $\Delta \phi$ diasumsikan sebagai fungsi kuadrat mean angle $\phi_{m}{ }^{2}$, sehingga :

$\Delta \phi=N \phi_{m}^{2}$

maka dengan menggunakan persamaan (1) Bertin's coefficient $N$ secara mudah dapat diperoleh :

$N=a / \phi_{m}+b$

dimana nilai $a$ dan $b$ diperoleh dengan metode least square, sehingga hasilnya dapat di gambarkan dalam sebuah plot fungsi yang disebut curve of extinction $\left(\phi_{m}, \Delta \phi\right), \Delta \phi=\phi_{n+1}-\phi_{n}$ dan $\phi_{m}=\left(\phi_{n+1}+\phi_{n}\right) / 2$. Bila persamaan umum gerak roll pada air tenang dituliskan seperti berikut :

$$
(I+\Delta I) \frac{d^{2} \phi}{d t}+N_{1} \frac{d \phi}{d t}+N_{2} \frac{d \phi}{d t}\left|\frac{d \phi}{d t}\right|+k \phi=0
$$

dimana $(I+\Delta I)$ mass moment inertia dan added mass moment inertia, $N_{1}$ dan $N_{2}$ adalah masingmasing linier dan quadratic roll damping moment, dan $k$ merupakan restoring moment. Energy dissipated pada roll decay untuk tiap setengah periode roll (T/2) merupakan integral dari persamaan (4), karena :

$$
\int_{0}^{T / 2}\left((I+\Delta I) \frac{d^{2} \phi}{d t}\right) \frac{d \phi}{d t} d t=0
$$

maka

$$
\int_{0}^{T / 2}\left(N_{1} \frac{d \phi}{d t}+N_{2} \frac{d \phi}{d t}\left|\frac{d \phi}{d t}\right|+k \phi\right) \frac{d \phi}{d t} d t=0
$$

jika gerak roll $\phi$ dituliskan dalam bentuk $\phi=A e^{i \alpha t} \cos \omega t$ maka akan diperoleh :

$\int_{0}^{T / 2}\left(N_{1} \frac{d \phi}{d t}\right) \frac{d \phi}{d t} d t=\frac{N_{1} \pi^{2}}{T} \phi^{2}$

$\int_{0}^{T / 2}\left(N_{2} \frac{d \phi}{d t}\left|\frac{d \phi}{d t}\right|\right) \frac{d \phi}{d t} d t=N_{2} \frac{16 \pi^{2}}{3 T^{2}} \phi^{\prime 3}$

$\int_{0}^{T / 2}(k \phi) \frac{d \phi}{d t} d t=-k \phi^{\prime} \Delta \phi$

Dari persamaan $(5) \sim(9)$ didapat :

$$
\frac{N_{1} \pi^{2}}{T} \phi^{\prime 2}+N_{2} \frac{16 \pi^{2}}{3 T^{2}} \phi^{\prime 3}-k \phi^{\prime} \Delta \phi=0
$$

$$
\Delta \phi=\frac{1}{k}\left(\frac{N_{1} \pi^{2}}{T}\right) \phi^{\prime}+\frac{1}{k}\left(N_{2} \frac{16 \pi^{2}}{3 T^{2}}\right) \phi^{\prime 2}
$$

Dari persamaan (11), bila $\phi^{\prime}=\phi_{m}$ maka didapatkan nilai koefisien $a$ dan $b$ pada persamaan decrement roll decay pada persamaan (1) masingmasing

$a=\frac{1}{k}\left(\frac{N_{1} \pi^{2}}{T}\right)$ dan $\quad b=\frac{1}{k}\left(N_{2} \frac{16 \pi^{2}}{3 T^{2}}\right)$

Sehingga akan didapat nilai $N_{1}$ dan $N_{2}$ dari uji roll decay. Nilai $a$ dan $b$ masing-masing menunjukkan sebagai besaran koefisien roll damping linier dan quadratik.

\section{HASIL DAN PEMBAHASAN \\ 3.1 Roll Decay Test}

Untuk mendapatkan data koefisen roll damping linier maupun quadratik dilakukan beberapa kali uji roll decay pada masing-masing Model-A dan Model-B. Hasil perekaman data time trace uji roll decay pada kedua buah model, lihat Gambar 2.
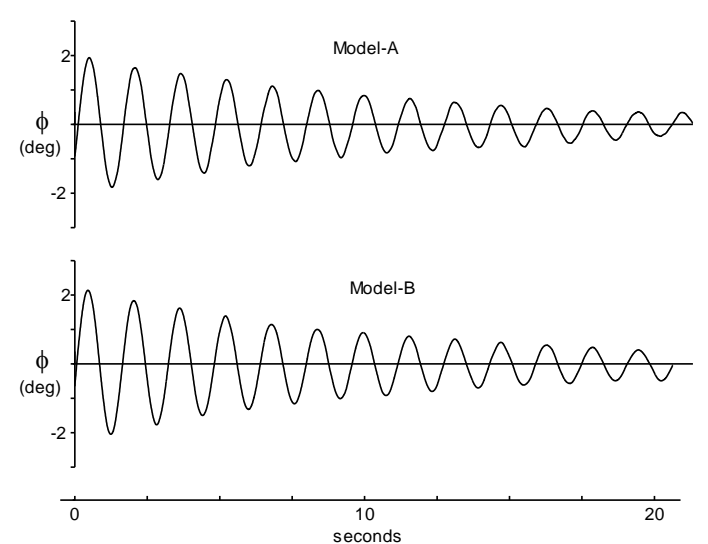

Gambar 2. Time traces uji roll decay untuk Model-A dan Model-B

Dari hasil pengujian tersebut didapatkan roll natural period $T_{\phi}$ untuk Model-A adalah 1.545 sec, sedangkan Model-B didapat $1.551 \mathrm{sec}$. Hasil pengujian menunjukkan hasil natural period yang sama, hal ini dimungkinkan karena titik berat meninggi $V C G$ dan jari-jari gyrasi roll $k x x$ adalah sama untuk kedua model.

Pada Gambar $3 \sim 6$ adalah gambar curve of extinction hasil uji roll decay. Penyajian data hasil uji roll decay untuk Model-A ditampilkan dengan simbol • dan $\circ$ masing-masing menujukkan nilai puncak positif (crests) dan negatif (troughs), 
begitu juga untuk data hasil uji Model-B dengan simbol $\square$ dan $\mathbf{m}$.

Gambar 3 dan 4 merupakkan hasil fitting data hasil uji roll decay dengan metode Froude, dari curve of extinction tersebut didapatkan nilai a dan b yang merupakan koefisien komponen linier dan quadratik roll damping. Sedangkan pada Gambar 4 dan 5 menggambarkan nilai koefisien $N$ atau Bertin's coefficient.

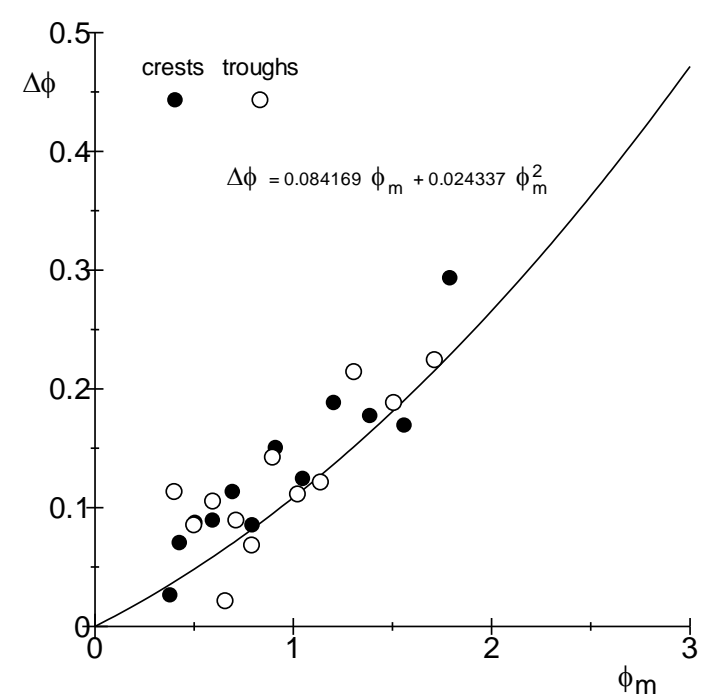

Gambar 3. Fitting roll damping koefisien pada Model-A

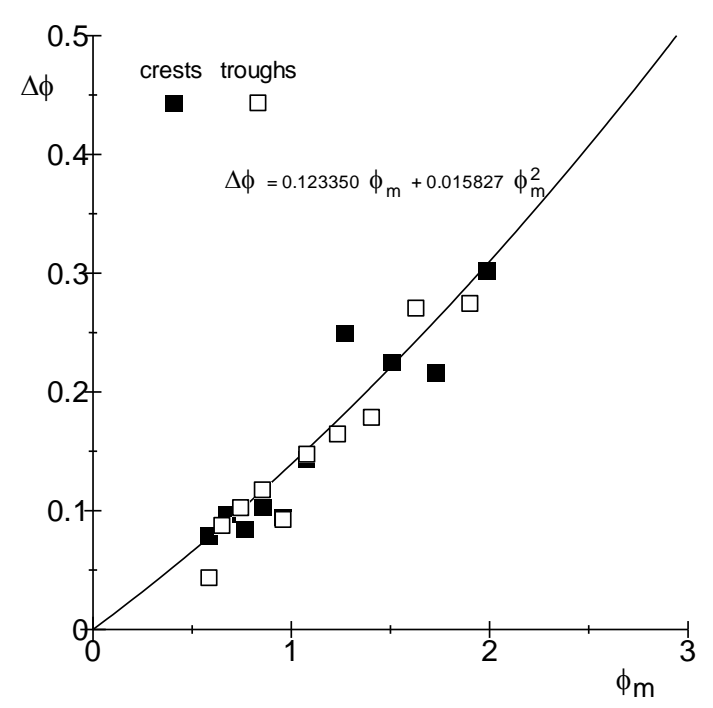

Gambar 4. Fitting roll damping koefisien pada Model-B

Dari hasil pengujian untuk masing-masing komponen roll damping disajikan dalam Tabel 2. Dari hasil tersebut terlihat bahwa, pengurangan panjang model barge dengan letak relatif titik berat sama menunjukkan penambahan nilai koefisien roll damping, kenaikan siknifikan terjadi pada komponen linier, namun sebaliknya terjadi penurunan pada komponen quadratiknya meskipun tidak siknifikan. Nilai total koefisien roll damping Model-B terjadi kenaikan 21\% dibandingkan Model-A.

Tabel 2. Koefisien damping hasil roll decay

\begin{tabular}{cccc}
\hline Model & $\boldsymbol{a}$ & $\boldsymbol{b}$ & $\boldsymbol{a}+\boldsymbol{b}$ \\
\hline $\mathrm{A}$ & 0,084169 & 0,024337 & 0,108506 \\
$\mathrm{~B}$ & 0,123350 & 0,015287 & 0,138637 \\
\hline
\end{tabular}

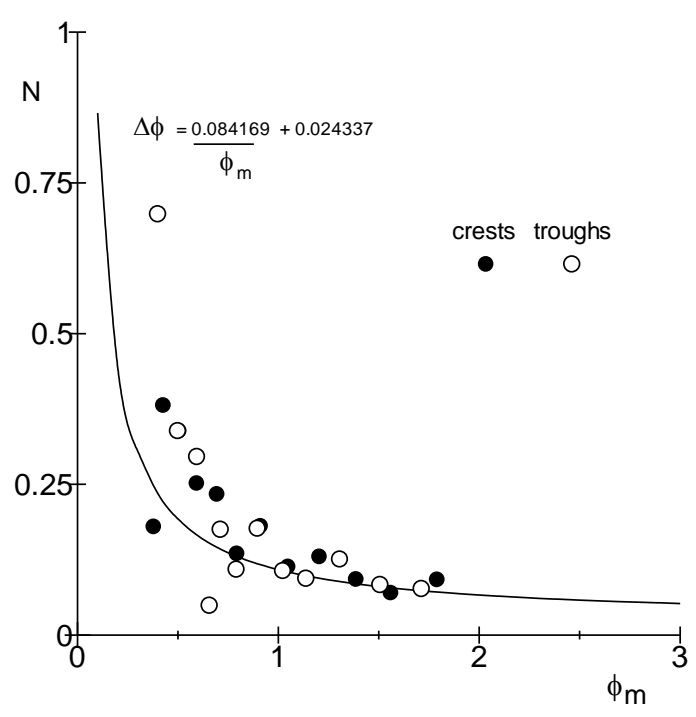

Gambar 5. N coefficients pada Model-A

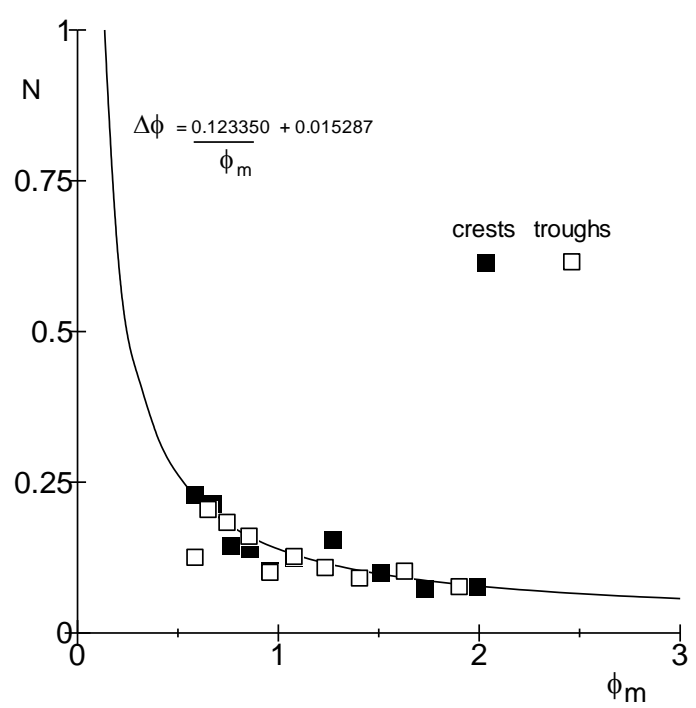

Gambar 6. $N$ coefficients pada Model-B

\subsection{Seakeeping Test}

Untuk mengetahui pengaruh perubahan roll damping terhadap gerak roll, maka dilakukan pengujian seakeeping pada kedua model tersebut dengan kondisi dan arah gelombang yang sama.

Hasil pengujian seakeeping kedua model tersebut ditampilkan dalam bentuk response amplitude operator (RAO) gerak roll seperti terlihat pada Gambar 7. Dari hasil tersebut 
menunjukkan bahwa kenaikan roll damping pada Model-B berpengaruh pada turunnya respon gerak roll, terutama pada posisi peak resonance. Kenaikan nilai roll damping pada Model-B yang tidak siknifikan, juga menyebabkan penurunan yang tidak siknifikan pada resonansi respon gerak rollnya. Puncak resonansi ini penting menjadi perhatian karena posisinya yang berimpit dengan roll natural frekuensi model yang menyebabkan respon gerak maksimum.

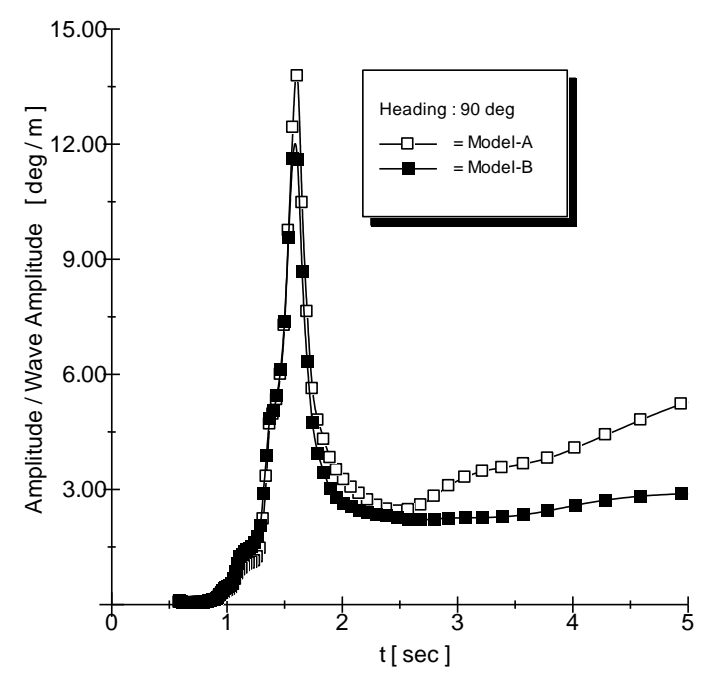

Gambar 7. RAO roll Model-A dan Model-B

\section{KESIMPULAN}

Dengan menggunakan uji roll decay didapatkan koefisien linier dan quadratik roll damping untuk kedua model FPU barge yang berbeda panjang. Akibat pengurangan panjang barge, namun dengan posisi relatif titik berat dan jari-jari girasi roll yang sama dengan model induk, didapatkan kenaikan nilai koefisien roll damping dengan didominasi pada kenaikan nilai komponen linier roll damping. Sehingga hal ini berpengaruh pada kinerja seakeeping, dari pengujian seakeeping membuktikan bahwa kenaikan nilai roll damping akan menurunkan respon gerak roll pada model yang lebih pendek.

\section{UCAPAN TERIMA KASIH}

Terimakasih kepada manejemen dan rekanrekan BTH-BPPT yang telah bersama-sama mendukung menyelesaikan kegiatan pengujian model FPU barge.
[1] H.R. Yuck, D.H. Lee, and H.S. Choi, "Estimation of Roll Damping Coefficients for Non-Conventional Mid-Ship Sections", Proc. of the 13th ISOPE Conference, Honolulu, USA, 2003.

[2] I.K. Park, H.S. Shin and J.W. Kim, "Effect of Roll Center Position on the Roll Damping of FPSO", Proc. of the 10th ISOPE Conference, Seattle, USA, 2000.

[3] Y. Ikeda, et al, "Roll Damping of a Sharp Cornered Barge and Roll Control by a New Type Stabilizer", Proc. 3th ISOPE Conf., Singapore, 1993.

[4] Y. Ikeda, B. Ali, and H. Yoshida, "A Roll Damping Prediction Method for a FPSO with Steady Drift", Proc. 14th ISOPE Conf., Toulon, France, 2004.

[5] A.C. Fernandes, and A.C. Oliveira, "The roll damping assessment aia decay model testing (new ideas about an old subject)," Journal of Marine Science and Application, 8, pp. 144150, 2009.

[6] A.C. Fernandes and A.C. Oliveira, "An Alternative to Model the Non Linear Roll Damping of a FPSO Hull," Journal of Marine Science and Application, 8, pp. 144-150, 2010.

[7] M. Fujino, et al., "Examination of Roll damping Coefficients and Effective Wave Slope Coefficient for Small Passenger Crafts", Proc. US Coast Guard Vessel Stability Symposium, 1993.

[8] S. Surendran, S.J. Lee, Reddy, and G. Lee, "Non-linear roll dynamics of a Ro-Ro ship in waves," Ocean Engineering, 32(14), 18181828, 2005.

[9] Froude, "On the Rolling of Ships", RINA Transactions and Annual Report 1861, London, UK, 1861. 